\title{
RANCANGAN APLIKASI SISTEM INFORMASI KEPEGAWAIAN PADA KANTOR CV. MEGA CIPTA PANGKALPINANG
}

\author{
Sujono \\ Program Studi Teknik Informatika \\ STMIK Atma Luhur \\ Email: rik_do100@yahoo.com
}

\begin{abstract}
ABSTRAK
Tujuan penelitian ini adalah menghasilkan sistem informasi kepegawaian secara komputerisasi dimana sistem kepegawaian sebelumnya masih menggunakan sistem manual, sehingga lebih efisien dan optimal guna mendukung kemajuan dan perkembangan kepegawaian tersebut. Dengan memanfaatkan sistem informasi pengolahan data karyawan, dapat meningkatkan kinerja serta pengolahan data yang lebih baik, tepat, cepat dan akurat. Hasil yang ingin dicapai dari penelitian ini adalah untuk membuat aplikasi sistem infornasi kepegawaian pada Kantor CV. Mega Cipta Pangkalpinang ini menjadi lebih terkomputerisasi dan mempermudah dalam pengolahan data pegawai. Peningkatan kinerja kerja tidak terlepas dari sarana dan prasarana, salah satunya adalah dukungan teknologi dan sistem informasi yang sesuai dengan kebutuhan. Daya saing sebagai dasar keunggulan ditentukan oleh kemampuan berkembang dan memahami perubahan perilaku atau organisasi (sistem) yang melibatkan kombinasi pemikiran, proses serta pemanfaatan secara efektif teknologi dan manusia guna menghasilkan sesuatu yang berbeda atau lebih baik. Sistem Informasi Kepegawaian pada Kantor CV. Mega Cipta Pangkalpinang ini merupakan sistem informasi kepegawaian yang dirancang dengan menggunakan metodologi berorientasi objek dengan alat bantu UML (Unified Modelling Language), pengamatan langsung dan wawancara dengan pihak yang terkait.
\end{abstract}

Kata kunci: kepegawaian, teknologi, aplikasi, sistem informasi, $U M L$, metodologi berorientasi objek.

\section{ABSTRACT}

The purpose of this research is to produce a computerized personnel information system where the previous personnel system still uses a manual system, making it more efficient and optimized to support the progress and development of the civil service. By leveraging data processing employee information system, can improve their performance and better data processing, precise, fast and accurate. The results to be achieved from this research is to make an application to the Office of the staffing system infornasi CV. Mega Cipta Pangkalpinang is becoming more computerized and simplify the processing of employee data. Improved performance of the work can not be separated from the infrastructure, one of which is the support of technology and information systems that suit their needs. Competitiveness as a basis of excellence determined by the ability to grow and understand the changing behavior or organization (system) which involves a combination of ideas, processes and effective use of technology and humans in order to produce something different or better. Office Information Systems Officer at CV. Mega Cipta Pangkalpinang a personnel information system that is designed using object oriented methodology with tools UML (Unified Modeling Language), direct observation and interviews with relevant parties.

Keywords: personnel system, technology, applications, information systesm, UML, object oriented methodology.

\section{PENDAHULUAN}

Perkembangan zaman yang semakin modern membuat teknologi saat ini semakin canggih .Hal ini memberikan pengaruhi yang besar pada aktivitas kerja. Manusia harus bisa mempunyai kemampuan dalam mengolah data sebuah system informasi secara tepat dan akurat karena hal tersebut tentunya akan sangat diperlukan dalam pekerjaan. Banyaknya peralatan berteknologi tinggi diciptakan agar dapat memudahkan pekerjaan manusia. Salah satunya adalah komputer.

Penggunaan komputer sangat banyak membantu masyarakat untuk kehidupan sehari-hari misalnya disekolah , kantor-kantor pemerintahan ataupun swasta,pusat perbelanjaan ataupun tempat-tempat lainnya. Karena sekarang penggunaan computer sangat besar sekarang ini banyak program aplikasi computer yang beredar diperusahaan mulai dari yang sederhana sampai yang sangat sempurna agar diharapkan dapat membantu memberikan informasi yang akurat dan cepat. Oleh karena itu perusahaanperusahaan diharuskan menggunakan sistem informasi kepegawaianyang terkomputerisasi untuk mengatasi masalah-masalah yang timbul yang dapat mengurangi produktivitas perusahaan. 
CV. Mega Cipta merupakan perusahaan dibidang pembuataan interior desain yang sangat dicari oleh masyarakat pangkalpinang. Perusahaan ini sangat pesat perkembangannya dengan ditunjukan banyaknya perusahaan-perusahaan swasta maupun pemerintah dan masyarakat yang berada di Bangka menggunakan jasa interior desain kantor CV.Mega Cipta. Seiring dengan meningkatnya perkembangan perusahaaan tersebut, perusahaan harus menambah jumlah karyawan dan dengan bertambahnya jumlah karyawan maka proses kepegawaianmenjadi masalah yang harus diatasi agar terhindar dari kekeliruan yang mengakibatkan produktivitas perusahaan menurun.

Sistem kepegawaian di kantor CV. Mega Cipta Pangkalpinang masih manual dan kurang efekti,. sehingga sering terjadi kekeliruan dikarenakan pengolahan data yang manual dan kurang efektif sehingga sering terjadi kesalahan dan keterlambatan data yang berhubungan dengan karyawan yang mengakibatkan kinerja yang tidak efektif, oleh karena itu untuk mendukung tugas perusahaan diperlukan bagian admin yang handal dan dapat menciptakan suasana karyawan yang baik dilingkungan perusahaan. Salah satunya adalah sistem informasi yang baik, jelas dan akurat sehingga bisa dijadikan panduan seberapa baik pelayanan CV. Mega Cipta Pangkalpinang. Informasi yang baik, jelas dan akurat dapat dijadikan untuk meyakinkan pelanggan bahwa CV. Mega Cipta adalah perusahaan yang dapat dipercayai.

Penelitian sebelumnya yang dilakukan oleh Aullya Rachmawati dalam procidingnya yang berjudul “ Perancangan Sistem Pendukung Keputusan Bagian Kepegawaian Pada SMK Muhammadiyah 1 Baturetno" [1], dimana sistem pengelolaan data kepegawaian sudah menggunakan sistem yang terkomputerisasi namun hanya sebatas pengolahan data saja, informasi yang dihasilkan belum digunakan sebagai dasar untuk pendukung proses pengambilan keputusan. Sehingga sistem yang sudah ada tersebut dikembangkan menjadi sistem informasi kepegawaian yang dapat mendukung proses pengambilan keputusan untuk pemberian reward dan punishment.

Berdasarkan hal tersebut, maka peneliti mencoba untuk membuat suatu rancangan sistem informasi kepegawaian yang terkomputerisasi dulu sehingga dalam pencarian data karyawan lebih mudah dan tidak adanya keterlambatan dalam penyampaian informasi. Peneliti menyadari bahwa dengan sistem yang terkomputerisasi juga mungkin masih terdapat kekurangan seperti dalam proses pengambilan keputusan. Namun peneliti mencoba mengembangkan aplikasi sistem kepegawaian ini secara bertahap.

Sistem Informasi berasal dari kata Sistem dan Informasi. Sistem adalah satu jaringan kerja dalam suatu prosedur yang paling berhubungan satu sama lain dengan maksud yang sama. "Informasi adalah data yang telah diproses yang memiliki arti.“[2]. Sedangkan menurut Wahyono Teguh, sistem adalah "Suatu kesatuan utuh yang terdiri dari beberapa bagian yang saling berhubungan dan berinteraksi untuk mencapai tujuan tertentu.’[3]. Adapun syarat-syarat sistem adalah sebagai berikut :

a. Sistem harus dibentuk untuk menyelesaikan masalah.

b. Elemen sistem harus mempunyai rencana yang ditetapkan.

c. Adanya hubungan diantara elemen sistem.

d. Unsur dasar dari proses (arus informasi, energi dan material) lebih penting dari pada elemen sistem.

e. Tujuan organisasi lebih penting dari pada tujuan elemen.

Dari definisi diatas dapat disimpulkan bahwa infomasi adalah data yang diolah menjadi bentuk yang lebih berarti bagi penerimanya dan bermanfaat dalam mengambil keputusan. Istilah informasi mengarah pada penggunaan teknologi komputer didalam organisasi untuk menyajikan infomasi kepada pemakai. Informasi juga merupakan hal yang sangat penting bagi manajemen didalam pengambilan keputusan.

Sistem Infomasi adalah "Sebagai satuan yang saling berhubungan yang mengumpulkan (mendapatkan komponen kembali), memproses, menyimpan dan mendistribusikan informasi untuk mendukung pengambilan keputusan dan kendali dalam suatu organisasi.’[4]

Konsep dasar berorientasi objek mencapai puncaknya pada saat masalah analisis dan desain menjadi lebih diperhatikan dari pada masalah coding. Analisa dan perancangan sistem berorientasi objek merupakan cara baru untuk menggambarkan suatu masalah dengan menggunakan model yang dibuat menurut konsep sekitar dunia nyata. Dalam hal ini dasar pembuatannya adalah objek, dimana objek tersebut merupakan kombinasi antara struktur data dan perilaku dalam suatu entitas. " Berorientasi Objek adalah kita mengorganisasikan perangkat lunak sebagai kumpulan dari objek tertentu yang memiliki struktur data dan perilaku."'[5]

Tools yang digunakan untuk menggambarkan objek-objek tersebut adalah UML (Unified Modelling Language). UML adalah "bahasa" yang telah menjadi standar dalam industri untuk visualisasi, merancang dan mendokumentasikan sistem perangkat lunak. Adapun tujuan utama $U M L$ antara lain untuk :

a. Memberikan model yang siap pakai, bahasa visual yang ekspresif untuk mengembangkan dan saling menukar model dengan mudah dan dimengerti secara umum. 
b. Memberikan bahasa pemodelan yang bebas dari berbagai bahasa pemrograman dan proses rekayasa.

c. Menyatukan praktek-praktek terbaik yang terdapat dalam pemodelan.

Untuk membuat suatu model, $U M L$ mendefinisikan diagram-diagram berikut ini :

$\begin{array}{cl}\text { a. } & \text { Usecase Diagram } \\ \text { b. } & \text { Class Diagram } \\ \text { c. } & \text { Behavior Diagram } \\ \text { d. } & \text { Statechart Diagram } \\ \text { e. } & \text { Activity Diagram } \\ f . & \text { Interaction Diagram } \\ g . & \text { Sequence Diagram } \\ h . & \text { Colaboration Diagram } \\ i . & \text { Component Diagram } \\ j . & \text { Deployment Diagram }\end{array}$

\section{METODOLOGI PENELITIAN}

Metodologi Penelitian yang digunakan dalam mengumpulkan informasi dan data-data yang diperlukan dalam penelitian ini adalah sebagai berikut :

a. Observasi; Dilakukan untuk mengumpulkan data dengan cara pengamatan langsung.

b. Wawancara; Mempelajari dan menganalisa sistem yang sedang berjalan serta mendapatkan data langsung dari sumbernya dengan tanya jawab. Dengan wawancara diharapkan informasi yang diperoleh benar-benar dapat dipertanggung jawabkan sesuai dengan pertanyaan yang diajukan.

c. Studi Kepustakaan; Dilakukan dengan cara membaca buku-buku yang berkaitan dengan sistem kepegawaian.

d. Analisa Sistem

Menceritakan proses bisnis atau alur kerja sebuah proses bisnis dan urutan aktivitas didalam proses pengolahan data kepegawaian dan menggunakan usecase diagram untuk menganalisa kebutuhan sistem dari sudut pandang user.

e. Perancangan Sistem dengan Class Diagram dan Rancangan Layar.

\section{HASIL DAN PEMBAHASAN}

\subsection{Proses Bisnis Sistem Berjalan}

Adapun proses bisnis sistem kepegawaianpada CV. Mega Ciptaadalah sebagai berikut :

a. Pendataan karyawan

Bagian Admin memberikan formulir data karyawan kesetiap dengan jabatan masing-masing, lalu karyawan mengisi formulir data karyawan kemudian mengembalikan lagi ke admin. Bagian admin memeriksa formulir data karyawan tersebut jika data karyawan sudah lengkap maka akan dicatat lalu diarsipkan dan jika belum lengkap maka formulir akan dikembalikan kepada karyawan tersebut untuk dilengkapi.

b. Pengajuan Masa Pensiun

Bagian admin mengajukan surat pengajuan masa pensiun karyawan yang akan memasuki masa pensiun kepada pimpinan. Kemudian pimpinan menyetujui dan menyerahkan kembali kepada bagian admin untuk membuat SK pensiun.

c. Pengajuan Cuti Tahunan

Karyawan mengajukan cuti tahunan kepada bagian admin. Bagian admin akan memeriksa apakah karyawan tersebut sudah cukup cuti atau belum. Jika karyawan tersebut sudah cukup cuti maka cuti tersebut akan ditolak. Jika belum akan diproses. Kemudian admin mengajukan surat pengajuan cuti tersebut kepada pimpinan untuk disetujui. Setelah disetujui maka bagian admin akan membuat surat cuti karyawan dan menyerahan surat cuti kepada karyawan.

d. Mutasi Karyawan

Sekretaris pimpinan menyerahkan surat mutasi karyawan kepada bagian admin kemudian bagian admin mencatat data mutasi karyawan. Setelah itu meyerahkan surat mutasi karyawan kepada karyawan. 
e. Surat Tugas

Pimpinan memerintahkan untuk membuat surat tugas kepada bagian admin. Kemudian admin membuat surat tugas dan menyerahkan kepada karyawan.

f. Kenaikan Gaji Berkala

Setiap 1 tahun sekali karyawan akan memperoleh kenaikan gaji berkala.Bagian admin akan memeriksa masa kerja karyawan. Jika tidak cukup tidak diproses dan Jika cukup bagian admin akan membuat surat kenaikan gaji berkala kemudian meyerahkan kepada pimpinan untuk disetujui. Setelah itu pimpinan menyerahkan kembali surat kenaikan gaji berkala kepada bagian admin.

\subsection{Analisa Dokumen Keluaran Sistem Berjalan}

Berikut ini adalah analisa dokumen keluaran pada sistem berjalan yang ada pada sistem informasi Kepegawaian pada Kantor CV. Mega Cipta Pangkalpinang adalah:

a. Nama Keluaran : Surat Cuti

Fungsi : Sebagai bukti tentang tanggal cuti karyawan

Media : Kertas

Distribusi : Karyawan

Rangkap : 1 (satu) lembar

Frekuensi : Setiap Tahun

Volume : 40/Tahun

Keterangan : Memuat informasi tentang karyawan yang mengambil cuti

Hasil Analisa : Kurang baik karena masih dilakukan secara manual sehingga tidak akurtanya data pemberian cuti kepada karyawan

b. Nama Keluaran : Surat Tugas

Fungsi : Sebagai bukti perintah tugas kepada karyawan

Media : Kertas

Distribusi : Karyawan

Rangkap : 1 (satu) lembar

Frekuensi : Setiap Tahun

Volume : 40/Tahun

Keterangan : Memuat informasi tentang keterangan perintah tugas

Hasil Analisa : Cukup baik sesuai kebutuhan karena memuat informasi yang diperlukan

c. Nama Keluaran: Surat Kenaikan Gaji Berkala
Fungsi
: Sebagai bukti keterangan kenaikan gaji berkala

Media

Distribusi : Karyawan

Rangkap : 1 (satu) lembar

Frekuensi : Seiap Tahun

Volume : 40/Tahun

Keterangan : Memuat informasi tentang keterangan perintah kenaikan gaji berkala

Hasil Analisa : Cukup baik sesuai kebutuhan karena memuat informasi yang diperlukan

d. Nama Keluaran: Surat Pengajuan Pensiun
Fungsi
Media
: Sebagai informasi untuk mengajukan masa persiapan pensiun karyawan
Distribus
: Kertas
Rangkap : 1 (satu) lembar
Frekuensi : Seiap Tahun
Volume : 40/Tahun
Keterangan : Memuat informasi tentang pengajuan karyawan yang akan memasuki masa persipan pensiun

Hasil Analisa : Kurang akuratnya data-data karyawan dan sering terjadi keterlambatan sehingga keputusan tersebut sering terlambat sampai ke karyawan 
e. Nama Keluaran: SK Pensiun

$\begin{array}{ll}\text { Fungsi } & \text { : Sebagai bukti keterangan pensiun } \\ \text { Media } & \text { : Kertas } \\ \text { Distribusi } & : \text { Karyawan } \\ \text { Rangkap } & : 1 \text { (satu) lembar } \\ \text { Frekuensi } & : \text { Seiap Tahun } \\ \text { Volume } & : \text { 40/Tahun } \\ \text { Keterangan } & : \text { Memuat informasi tentang keterangan pensiun karyawan } \\ \text { Hasil Analisa } & : \text { Cukup baik sesuai kebutuhan karena memuat informasi yang diperlukan }\end{array}$

\subsection{Analisa Dokumen Masukan Sistem Berjalan}

Berikut adalah analisa dokumen masukan pada sistem berjalan yang ada pada sistem informasi Kepegawaian pada Kantor CV. Mega Cipta Pangkalpinang adalah:

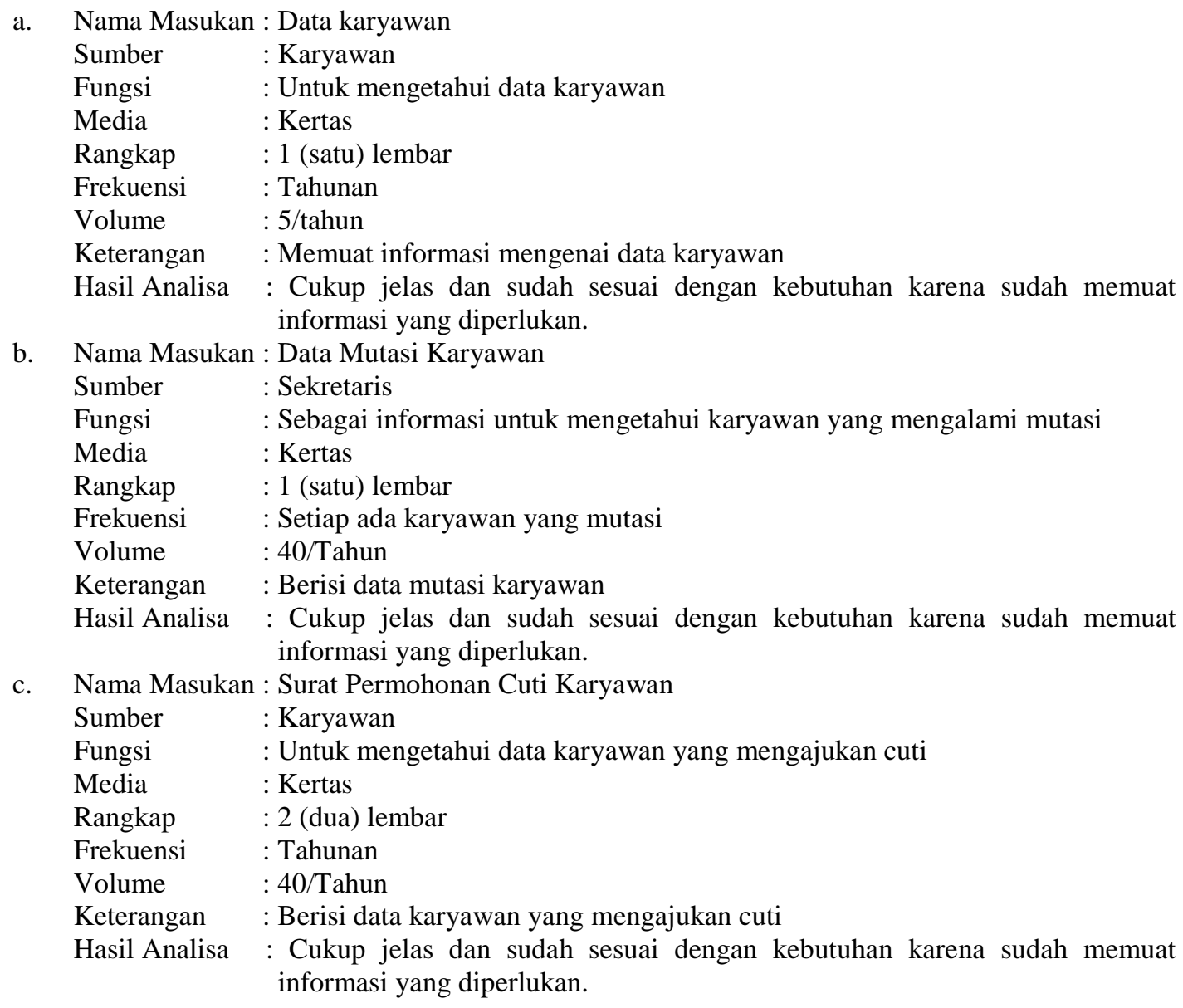

\subsection{UseCase Diagram Sistem Usulan}

Use case diagram digunakan untuk menggambarkan kebutuhan dan fungsionalitas sistem dari sudut pandang user berdasarkan hasil analisa yang telah dilakukan yang terfokus pada sistem yang terkomputerisasi. Adapun usecase diagram sistem usulan tersebut adalah sebagai berikut :

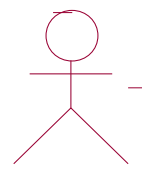

Bag. Admin

\section{Entry Data Pegawai}

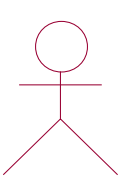

Pegawai

Gambar 1. UseCase Diagram Master Sistem Usulan 


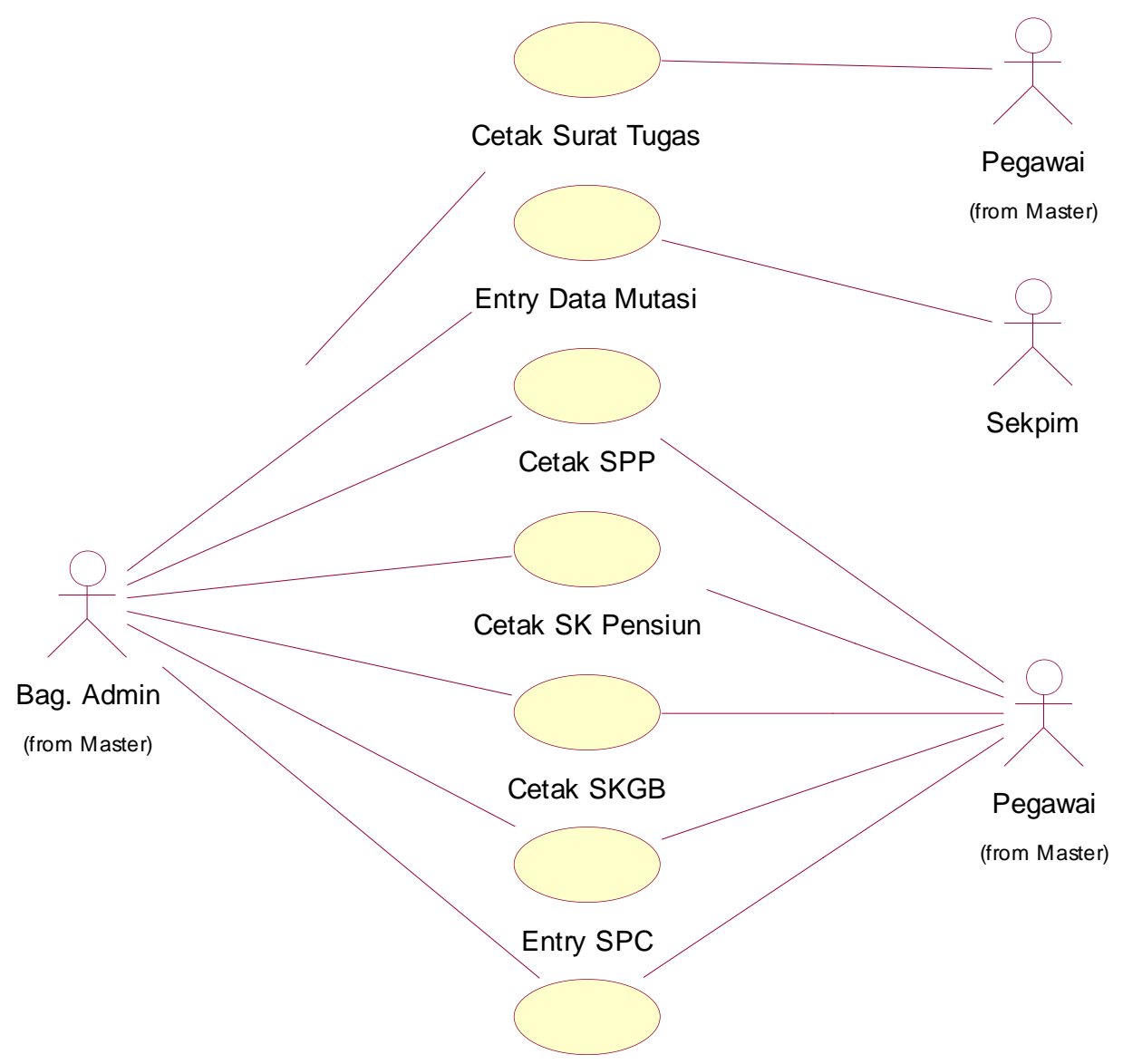

Cetak Surat Cuti

Gambar 2. UseCase Diagram Transaksi Sistem Usulan

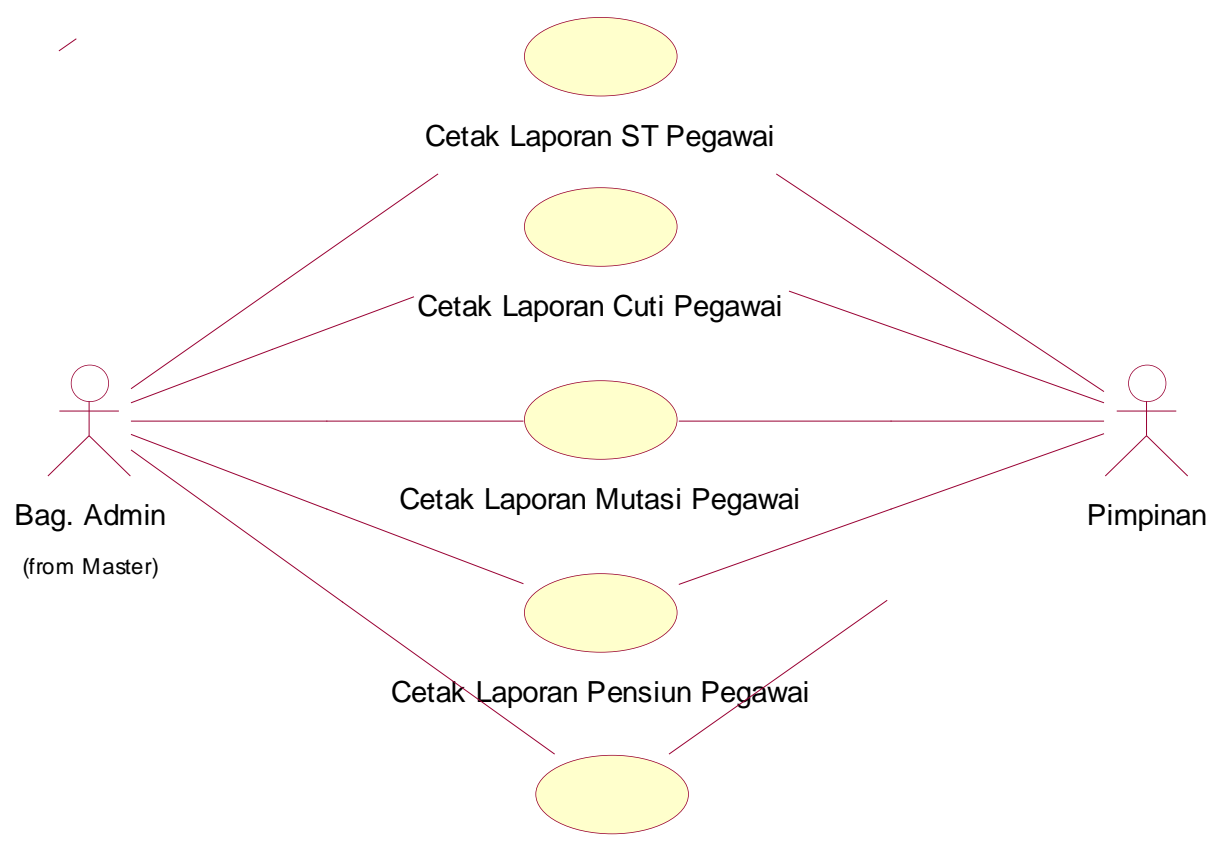

Cetak Laporan KGB Karyawan

Gambar 3. UseCase Diagram Laporan Sistem Usulan 


\subsection{Rancangan Basis Data}

Alat bantu yang digunakan dalam perancangan basis data adalah Class Diagram yaitu untuk menggambarkan entitas-entitas apa saja yang terlibat dalam sistem informasi Kepegawaian pada Kantor CV. Mega Cipta Pangkalpinang [6], yang terlihat pada gambar berikut ini :

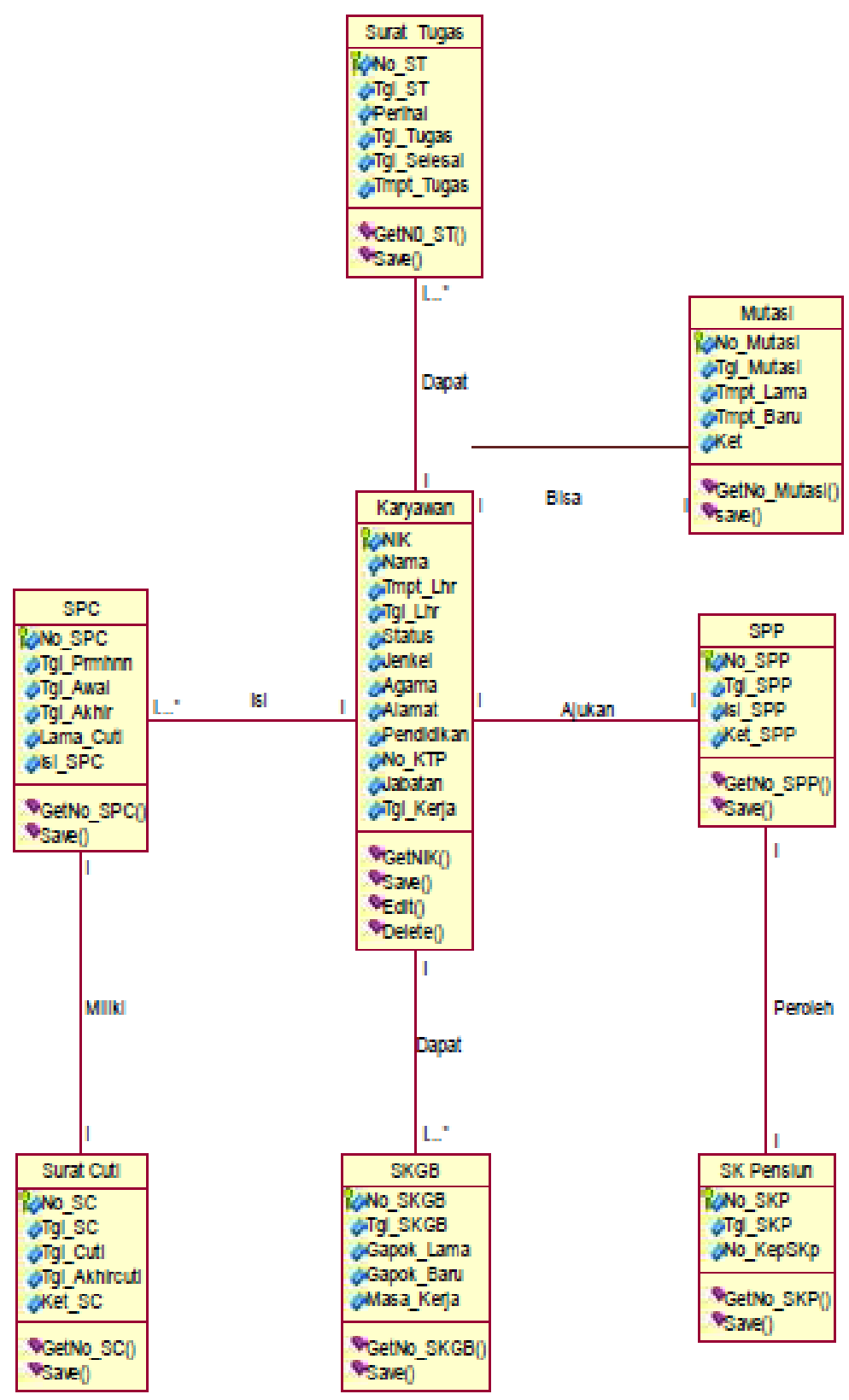

Gambar 4. Class Diagram

\subsection{Rancangan Layar}

Adapun beberapa contoh rancangan layar yang dirancang pada sistem ini adalah sebagai berikut : 


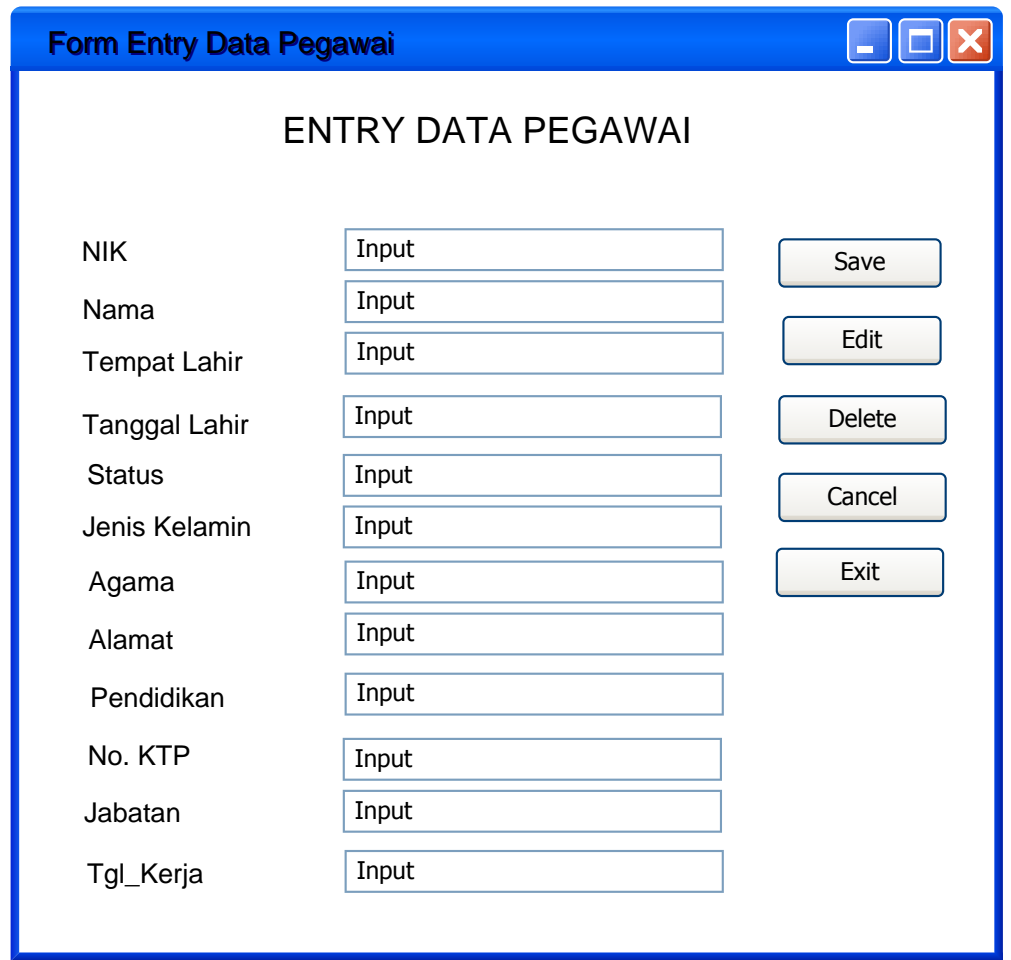

Gambar 5. Rancangan Layar Entry Data Pegawai

Rancangan layar diatas digunakan untuk mengentri data pegawai yang ada di CV. Mega Cipta Pangkalpinang.

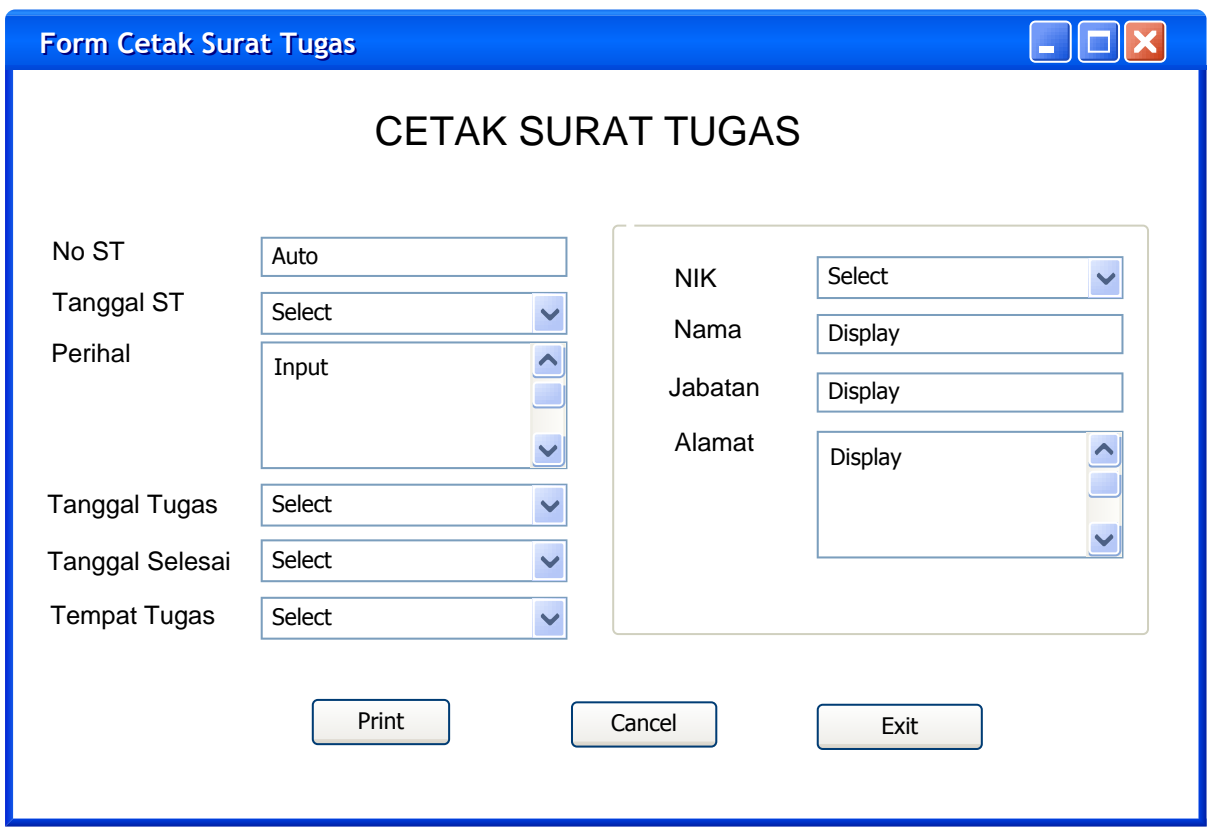

Gambar 6. Rancangan Layar Cetak Surat Tugas

Rancangan layar diatas digunakan untuk mencetak surat tugas bagi pegawai yang mendapat tugas dinas pada CV. Mega Cipta Pangkalpinang. 


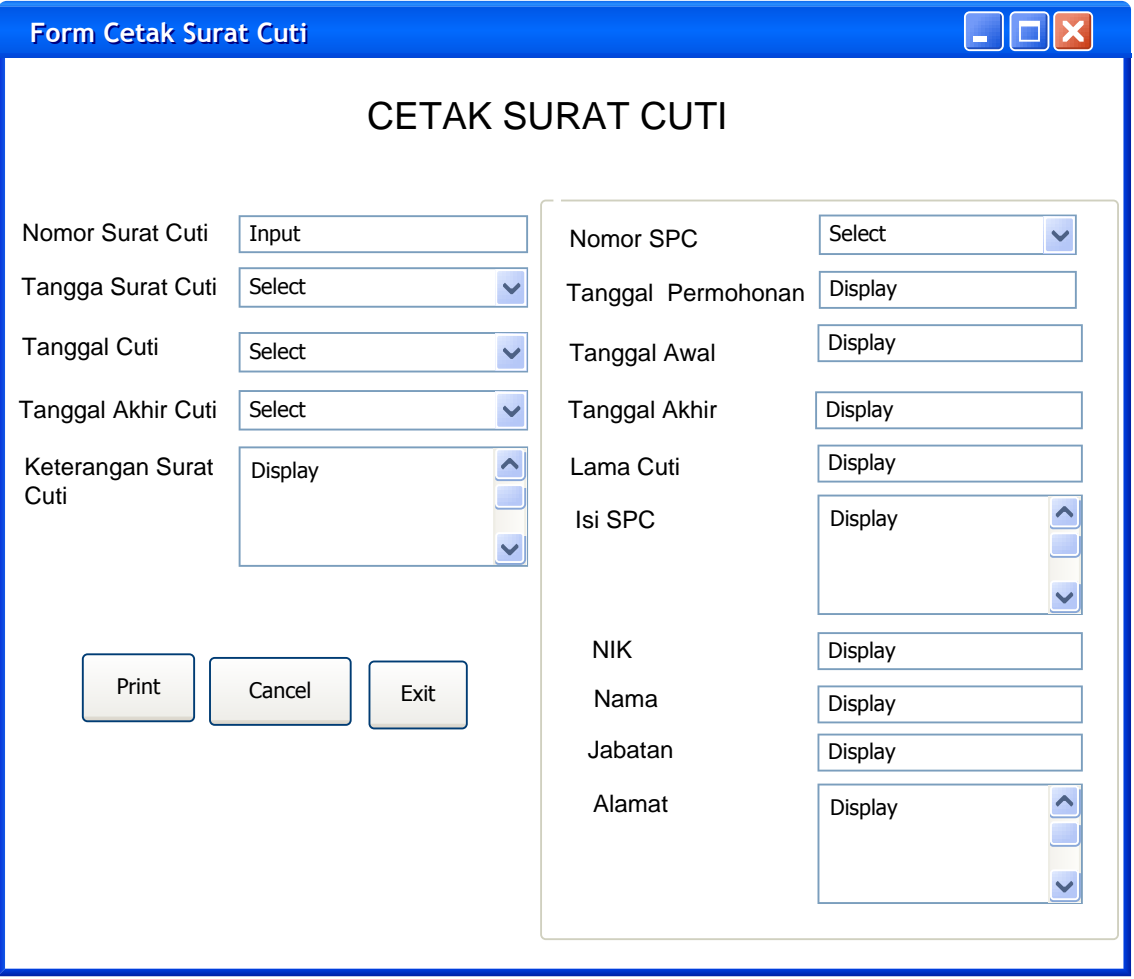

Gambar 7. Rancangan Layar Cetak Surat Cuti

Rancangan layar diatas digunakan untuk mencetak surat cuti pegawai yang mengajukan cuti tahunan pada CV. Mega Cipta Pangkalpinang.

\section{Form Cetak Laporan KGB Pegawai \\ CETAK LAPORAN KENAIKAN GAJI BERKALA PEGAWAI}
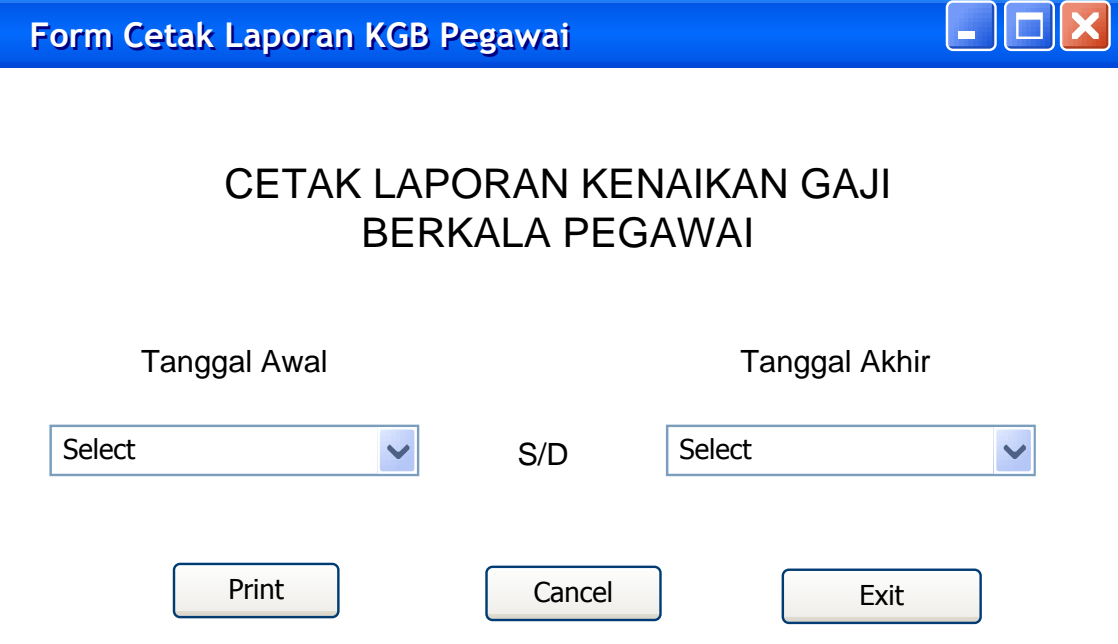

Gambar 8. Rancangan Layar Cetak Laporan Kenaikan Gaji Berkala

Rancangan layar diatas digunakan untuk mencetak laporan kenaikan gaji berkala pegawai yang ada di CV. Mega Cipta Pangkalpinang. 


\section{KESIMPULAN}

Berdasarkan hasil analisa yang sudah dilakukan, maka kesimpulan yang dapat diambil dari uraian di atas adalah sebagai berikut:

1) Dengan sistem berbasis komputer diharapkan dapat mempermudah dalam menyimpan dan mengolah data kepegawaian secara akurat dan tepat.

2) Dengan menggunakan sistem berbasis komputer ini dapat menghemat waktu dan mengurangi kemungkinan terjadinya kesalahan dan diharapkan dapat meningkatkan kinerja karyawan.

3) Dengan adanya sistem berbasis komputer ini bisa dengan mudah untuk membantu mengetahui data-data yang dibutuhkan dengan cepat dan dapat mengurangi jumlah waktu dan biaya yang dibutuhkan.

4) Penyimpanan dalam database memudahkan dalam pemeliharaan data sehingga kita tidak perlu menyimpan data-data pada media kertas yang mudah rusak seperti pada sistem manual.

5) Semua data - data bisa tersimpan keseluruhan sehingga kecil kemungkinan adanya kehilangan data saat akan membuat laporan.

6) Laporan karyawan dapat lebih mudah dibuat, cepat dan akurat sehingga bisa dilaporkan tepat waktu.

Adapun saran-saran untuk penelitian lanjutan pada CV. Mega Cipta yaitu :

1) Penelitian selanjutnya dapat dikembangkan pada bidang lain selain sistem informasi kepegawaian.

2) Penelitan selanjutnya dapat membangun sistem kepegawaian yang dapat mendukung proses pengambilan keputusan untuk pemberian reward dan punishment.

\section{DAFTAR PUSTAKA}

[1] Rachmawati, Aullya, (2013). Perancangan Sistem Pendukung Keputusan Bagian Kepegawaian Pada SMK Muhammadiyah 1 Baturetno, Prosiding SemNasTEKNOMEDIA STMIK AMIKOM Yogyakarta, Indonesia.

[2] Kadir, Abdul. (2003). Pengenalan Sistem Informasi. Edisi Pertama. Yogyakarta: ANDI.

[3] Teguh, Wahyono. (2004). Sistem Informasi : Konsep Dasar, Analisis Desain dan Implementasi. Edisi Pertama. Yogyakarta : Graha Ilmu.

[4] Jogiyanto, HM. (2005). Sistem Teknologi Informasi. Yogyakarta : ANDI.

[5] Sutopo, Ariesto Hadi. (2002). Analisis dan Design Berorientasi Objek. Yogyakarta : J dan J Learning.

[6] Tarlinda, Indah, (2015). Sistem Informasi Pengolahan Data Karyawan pada CV. Mega Cipta Pangkalpinang. Kuliah Praktek : Pangkalpinang. 